\title{
The Effect of Membrane Structure Prepared from Carboxymethyl Cellulose and Cellulose Nanofibrils for Cationic Dye Removal
}

\author{
Selestina Gorgieva ${ }^{1} \cdot$ Robert Vogrinčič ${ }^{1} \cdot$ Vanja Kokol $^{1}$ (i)
}

Published online: 30 November 2018

(c) The Author(s) 2018

\begin{abstract}
Water-stable and eco-friendly membranes were fabricated from carboxymethyl cellulose (CMC) acting as anionic adsorbent and cellulose nanofibrils (CNFs) as strengthening filler by solvent- and unidirectional freeze-casting processes, both supported with simultaneous citric acid (CA) mediated cross-linking. Spectroscopic, thermogravimetric and potentiometric titration techniques were applied to evaluate the efficacy of the cross-linking as well as to quantify the processing-dependant surface charge. In addition, the $\mathrm{CMC} / \mathrm{CNF}$ assembling and membrane porosity were identified microscopically as the combinatorial effect of components ratio and the applied fabrication technique. Finally, the membrane's cationic dyes adsorption capacity and kinetic were evaluated depending on the dyes ionization constants, solution $\mathrm{pH}$, and the contact time using batch equilibrium experiment, and further evaluated for filtration performance at optimal $\mathrm{pH}$. The resulting, freeze-casted membranes demonstrate anisotropic to isotropic and highly (>90\%) porous structures with gradient pore sizes (from few nm up to $200 \mu \mathrm{m}$ range). This provides relatively high and stable flux rates $\left(150-190 \mathrm{~kL} / \mathrm{m}^{2} \mathrm{~h} \mathrm{MPa}\right)$ with $\sim 100 \%$ cationic dye adsorption, fast dynamic (8.536-5.446 kg/g min) and capacity (1828-1398 g/kg), which highlight their potential in dead-end filtration technologies without need for additional separation step. The similar dye adsorption capacity was assessed for denser and nano-porous $(<50 \mathrm{~nm})$ solvent-casted membranes, however, with much lower and time-declining flux rates $\left(100-10 \mathrm{~L} / \mathrm{m}^{2} \mathrm{~h}\right.$ $\mathrm{MPa}$ ), demonstrating their potential usage in spiral wound-cross-flow modules. Both types of membranes anyhow showed high dye removal capacity ( $\geq 90 \%$ ) even after 4th (solvent-casted) and 50th (freeze-casted) reusing cycle, present a highvalue alternative to commercial activated carbons or other bio-nano-absorbents.
\end{abstract}

Keywords Carboxymethyl cellulose $\cdot$ Cellulose nanofibrils $\cdot$ Casting $\cdot$ Membrane $\cdot$ Dye removal

\section{Introduction}

The highly coloured wastewaters discharged from industrial and agricultural industries cause serious threats to the environment, not only because of their potential toxicities, carcinogenicity and non-biodegradability but also due to their visibility problems, have thus been the targets of great attention over recent years [1]. Compared with chemical and biological technologies, such as chemical coagulation and oxidation, photo-catalysis oxidation, biological oxidation $[2,3]$ etc, pressure-driven membrane filtration has emerged as a promising physical treatment method for separating,

Vanja Kokol

vanja.kokol@um.si

$1 \quad$ Faculty of Mechanical Engineering, Institute of Engineering Materials and Design, University of Maribor, Smetanova ul. 17, 2000 Maribor, Slovenia concentrating as well as purifying dye solutions, bringing the advantages of facile and green operation, high efficiency and low cost. However, although the nano-filtration process has proved to be highly effective for dye removal ability due to the small (200-1000 Da) molecular mass cut-off of membrane nanopore sizes $(1-10 \mathrm{~nm})$ [4], its application potential has been limited due to its considerable high operational pressure (and thus the energy costs) for achieving high permeation flux, as well as serious flux decline owing to membrane fouling [5, 6]. On the other hand, the ultra-filtration process, promoting the separation of molecules based on size at a relative low pressure (0.04-1 MPa), consumes relatively less energy [7], however, the removal of small molecules and dissolved contaminants (as dyes) cannot be accomplished due to the relatively larger pore size $(0.01-0.1 \mu \mathrm{m})$ and thus has to be combined with other technologies such as adsorption and coagulation during the pre-treatment step $[8,9]$. 
Several investigations have been reported recently using low-cost, industrial and agricultural waste-based, adsorbent materials of different sources and compositions, paying particular attention to the nature and porosity of adsorbents $[1,10]$. As the size of an adsorbent may play a key role in the adsorption behaviour (equilibrium and kinetics), especially when being within a nano-scale range, activated carbon is still the more commonly studied owing mainly to its highly porous structure and high surface area capable of fast and efficient adsorption (between 10 and $1000 \mathrm{~g} / \mathrm{kg}$ ) of a broad range of different dyes [11, 12]. Moreover, the addition of activated carbon into the membrane structure may reduce membrane fouling and prolong its lifetime [2, 13]. Nanocellulose as effective alternative have also aroused considerable interest recently [14-16], in the light of their lightness, highly specific surface area [17], mechanical and chemical properties [17]. The CNFs in particular have strong networking abilities, which are utilized in bionanocomposites processing where they act as a reinforcing matrix [18, 19]. In order to meet demanding industrial applications and provide high-tech performances with extended lifespan, a variety of surface modifications have been thus proposed $[20,21]$, providing compatible and mechanically-sufficient interfacial adhesion. The charge introduced has proved to have positive impact not only on nanocellulose dispersibility [22], but also on spatial distribution within the polymer matrices [23], and in the same way increased dye adsorption capacities [24-26].

It is generally believed, that the nanoparticles, being embedded within the micro-or ultra-filtration polymeric membranes, increasing the membranes' permeability as well as permeate quality, and by this may distinctly overcome the need for additional separation steps. It is also known, that $\mathrm{CMC}$, as a highly-efficient $(50-900 \mathrm{~g} / \mathrm{kg})$ polymeric adsorbent for cationic dyes [27], form fully transparent but physically unstable and manipulation weak film, when immersed in water. The addition of CNFs with the similar surface energy [28] may improves the system for a short period, however, the membrane would again failed after aqueous exposure due to the lack of chemical integrating and extremely high swelling, causing weakening of the interfibrillar bonds [29]. The aim of the presented study was thus (1) to fabricate water-stable membranes from CMC acting as ionic adsorbent and CNFs as the stabilizing and structural filler by using non-toxic CA as a cross-linker, and (2) to evaluate the membranes cationic dyes adsorption capacity and kinetic, as well as filtration performance (dye removal and flux rate) in relation with their fabrication routes (solvent- vs. freeze-casting process).

\section{Experimental}

\section{Materials}

CNFs were supplied by the University of Maine, USA (http://umaine.edu/pdc/nanofiber-r-d/). The CMC with $\mathrm{Mw}=250000 \mathrm{~g} / \mathrm{mol}$ and DS of $0.65-0.85$, anhydrous citric acid (CA), and florescent Rhodamine B Isothiocyanate (RBITC) dye were purchased from Sigma Aldrich and used without further purification, except otherwise stated. Two cationic dyes, Methylene blue (MB; C.I. 52015, Mw of $286.42 \mathrm{~g} / \mathrm{mol}$ ) and Basic Red 1 (BR; C.I. 45160, Mw of $444.36 \mathrm{~g} / \mathrm{mol}$ ) were purchased from TCI Chemicals, India.

\section{Preparations of Membranes}

The CMC was dissolved in deionised water at $1 \% \mathrm{w} / \mathrm{v}$ concentration by $24 \mathrm{~h}$ of magnetic stirring, until achieving a moderately viscous and transparent solution. In parallel, $2 \% \mathrm{w} / \mathrm{v}$ of CNF's water dispersion underwent the homogenization process (at room temperature for $3 \mathrm{~min}$ at $1000 \mathrm{~min}^{-1}$ by using a homogenizer IKA) in order to avoid the presence of large, agglomerated particles. The mixtures from different $\mathrm{v} / \mathrm{v}$ ratios of CNFs dispersion and CMC solution (4/4 and 7/1, 8/8 and 14/2) were prepared in glass bakers, following the separate addition of $1.6 \mathrm{~mL}$ CA with concentration of 5 and $10 \mathrm{wt} \%$ in respect to CNF and $\mathrm{CMC}$ total masses. The homogenization process was further improved by the addition of $4 \mathrm{~mL}$ of deionised water and after sufficient vortexing the final dispersions of $13.6 \mathrm{~mL}$ (for $4 / 4,7 / 1$ ) and $21.6 \mathrm{~mL}$ (for $8 / 8$ and 14/2) were separately poured into Teflon Petry dishes with diameters of $50 \mathrm{~mm}$. The pure CMC solutions and CNF dispersions were prepared in parallel following the same procedure. Two manufacturing processes, i.e. (i) solvent-casting and (ii) unidirectional freeze-casting, both followed by $24 \mathrm{~h}$ drying at $60^{\circ} \mathrm{C}$, were applied for nanocomposites' processing into differently structured membranes. The freeze-casting process was performed on a temperaturecontrolled (by the software programme Supercool®) $\mathrm{Cu}$ plate of a self-constructed cryo-unit with a temperature set to $-16{ }^{\circ} \mathrm{C}$ for $2 \mathrm{~h}$ to allow the cryogelation process and formation of the porous structure, followed by additional $20 \mathrm{~h}$ freezing in a freezer at $-20^{\circ} \mathrm{C}$ before drying. The obtained membranes were washed with distillate waters for CA residuals' removal, being followed by $\mathrm{pH}$ and conductivity measurements and further fridge-stored to the following analysis. 


\section{CNFs Fluorescent Labelling}

In order to trace the CNFs assembling within different compositions using Confocal Fluorescence Microscopy (CFM) (Leica DMI6000 CSF, Germany), the CNFs were primarily labelled with RBITC dye, according to the following procedure: $20 \mathrm{mg}$ of RBITC dye was added to $25 \mathrm{~mL}$ of $2 \% \mathrm{w} / \mathrm{w} \mathrm{CNFs}$ with vigorous stirring and $\mathrm{pH}$ adjustment to 13 with step-wise additions of $1 \mathrm{M} \mathrm{NaOH}$. The resulting CNF-dye dispersion was incubated in the dark for 4 days, being afterwards 5 times washed with EtOH by centrifugation at 6500 for $10 \mathrm{~min}$, and additionally dialyzed at dark against water in 12-14 kDa MWCO membrane (Spectra/Por $\left.{ }^{\circledR}\right)$ for several days. Dialysis was followed spectroscopically at the absorbance of $552 \mathrm{~nm}$.

\section{Evaluation of CA-Mediated Cross-Linking}

Attenuated Total Reflectance- Fourier Transform Infrared (ATR-FTIR) spectroscopy was performed on a Perkin-Elmer IR spectrophotometer with a Golden Gate ATR attached to a diamond crystal. The spectra were collected at ambient conditions from accumulating 16 scans at a $4 \mathrm{~cm}^{-1}$ resolution over a region of $4000-650 \mathrm{~cm}^{-1}$, with air spectrum subtraction performed in parallel as a background. The Spectrum 5.0.2 software program was applied for the data analysis.

${ }^{13}$ C CP/MAS Solid-State Nuclear Magnetic Resonance (NMR) spectroscopy analyses were performed on a solidstate NMR spectrometer (Agilent Technologies NMR System, $600 \mathrm{MHz}$ ) using $3.2 \mathrm{~mm}$ NB Double Resonance HX probe. Pieces of dry membranes and powdered CA were analysed under the following conditions: resonance frequency of $150.83 \mathrm{MHz}$, spinning rate of $16 \mathrm{kHz}, 1000$ scans with $5 \mathrm{~s}$ delays between each, at $25^{\circ} \mathrm{C}$ and using hexamethylbenzene $\left(\mathrm{C}_{12} \mathrm{H}_{18} ; \delta 17.3 \mathrm{ppm}\right)$ as a standard. The PeakFit v4.12 program software was applied for spectral deconvolution after linear background subtraction, being followed by Gaussian curve fitting. The areas of peaks related to crystalline cellulose were used for calculating the crystalline index $(\mathrm{CI}=\mathrm{C} 4 \mathrm{c} / \mathrm{C} 6 \mathrm{c})[30]$.

Thermal analyses were performed by means of Differential Scanning Calorimetry (DSC) and Thermo-gravimetric Analysis (TGA) using a TGA/DSC1 STAR ${ }^{\mathrm{e}}$ System, Mettler Toledo. Differences in transition temperatures and temperature/mass curve profiles were traced as being potentially introduced by the esterification process. The $24 \mathrm{~h}$ pre-conditioned (under standard atmosphere) membrane pieces were sealed at the bottoms of $\mathrm{Al}$ pans at volumes of $40 \mu \mathrm{L}$ in order to secure identical heat transfers of all samples, using the empty pan as a reference. The thermal analyses were scanned in the range between 25 and $600{ }^{\circ} \mathrm{C}$ with a heating rate of $5{ }^{\circ} \mathrm{C} / \mathrm{min}$.

\section{Scanning Electron Microscopy (SEM) and CFM Imaging}

Membranes imaging was performed by SEM within a magnification range of $250 \times$ to $15,000 \times$ using high-vacuum Sirion NC 400 and low-vacuum Quanta 3D instrumentation. Before the imaging, the sample pieces were mounted using double-sided carbon tape, sputter coated with gold and examined with the microscope at different positions. The pore size for each was calculated from obtained micrographs, by using the Image J. Pro6.2 software program.

The visualization of membranes in wet state was performed by CFM imaging, using the RBITC-labelled CNFcontaining samples. For that purpose, the fully wet membranes were positioned on a transparent glass holder above the 20× objective of an inverted CFM unit Leica TCS SP5 II. The excitation $\left(\lambda_{\mathrm{ex}}=540 \mathrm{~nm}\right)$ and emission $\left(\lambda_{\mathrm{em}}=573 \mathrm{~nm}\right)$ wavelengths were set according to RBITC. High-resolution images $(1024 \times 1024$ pixels) were obtained by light gain tuning and 8 times line averaging. For thin, solvent-casted membranes, the $\mathrm{z}$-stack was performed trough signal-limited thickness. Analysis was done off-line using Leica Application Suite X software (LAS X, Leica Microsystems).

\section{Porosity Measurements}

Mercury-intrusion porosimetry was applied for determining the total surface area and pore size distribution of freezecasted membranes (approximate dimensions $1 \times 1 \mathrm{~cm}$ ) by using the Pascal 140 computer-aided Mercury Intrusion Porosimeter (Thermo Fisher Scientific Inc.), which measures the pores within the $3.8-120 \mu \mathrm{m}$ diameter range and operate under pressure of $1-400 \mathrm{kPa}$.

Due to the pressure instability of the solvent-casted film-like membranes, the argon adsorption analysis was performed for these type of membranes to determine the specific surface areas and pore-size/volume rations by using Micromeritics Asap 2020 MP, according to BET and BJH methods, respectively. The samples were degassed prior to measurements at $100{ }^{\circ} \mathrm{C}$ for $20 \mathrm{~h}$ under dry $\mathrm{N}_{2}$ flow and $-196{ }^{\circ} \mathrm{C}$ to remove the excess of moisture and potential contaminations.

\section{Potentiometric Titration}

Potentiometric titration of CNF water dispersions being the same for the selected membranes was performed for quantifying the processing-dependant surface charge contribution. The titration was carried out using a dual-burette instrument Mettler Toledo T70, within an inert $\left(\mathrm{N}_{2}\right)$ atmosphere, being filled with $0.1 \mathrm{M} \mathrm{HCl}$ and $0.1 \mathrm{M} \mathrm{KOH}$. All the solutions were prepared in deionised water. The titration was performed in a back and forth manner, between $\mathrm{pH} 2.5$ and $11(0.1 \mathrm{M})$. 
Different titrant volumes $(0.001-0.25 \mathrm{~mL})$ were dynamically added within $30-80$ s periods. Blank $\mathrm{HCl}-\mathrm{KOH}$ titration was carried out under the same conditions. The $\mathrm{pH}$ value was measured using a Mettler Toledo DG-117 combined glass electrode.

\section{Membranes' Performance}

\section{Cationic Dyes Adsorption and Desorption Evaluated by UV- Vis Spectroscopy}

The adsorption parameters (adsorption capacity and kinetic) of membranes towards two cationic dyes with different ionization constants, i. e. $\mathrm{MB}(\mathrm{pKa}<1)$ and $\mathrm{BR}(\mathrm{pK}=6.13)$, were determined by batch equilibrium experiment. For that purpose, the membranes pieces with known dry weight were immersed in $100 \mathrm{~mL}$ of selected dye solution with concentration of $5 \mathrm{mg} / \mathrm{L}$ and $\mathrm{pH}$ adjusted to $4,6.5$ and 8.5 using $0.1 \mathrm{M} \mathrm{NaOH}$ and $0.1 \mathrm{M} \mathrm{HCl}$. After pre-determined incubation intervals (within $0.5-24 \mathrm{~h}$ ) under isothermal conditions $\left(23^{\circ} \mathrm{C}\right)$ and continuous shaking $\left(100 \mathrm{~min}^{-1}\right), 300 \mu \mathrm{L}$ aliquots of incubation (dye) media were withdrawn and optical absorption evaluated at $661 \mathrm{~nm}$ (for MB) and $524 \mathrm{~nm}$ (for BR) by a plate-reader equipped Tecan UV-Vis spectrophotometer. The removal of dye as per unit of sorbent/membrane dry weight $(\mathrm{g} / \mathrm{kg})$ and in the percentage (\%) is calculated using the following equation:

$Q_{t}=\left(C_{0}-C_{t}\right) \mathrm{V} / \mathrm{m}(\mathrm{g} / \mathrm{kg})$

Removal $=\frac{\left(C_{0}-C_{t}\right)}{C_{0}} \times 100(\%)$

where $C_{0}$ and $C_{t}(g / L)$ are concentrations of the initial and after pre-determined immersion times $(t)$ solutions, $V$ is the volume of dye solution $(L)$, and $m$ is the mass of adsorbent/ membrane $(\mathrm{kg})$. The amount of dyes that was adsorbed $\left(Q_{t}\right)$ was plotted against the time $(t)$, and further analyzed using pseudo-second-order kinetic model by giving the straight line curve fitted $t / Q t$ vs. $t$ plots to obtain the kinetic parameters: the kinetic constant $(k)$, and the equilibrium adsorption capacity $\left(Q_{e}\right)$ of adsorption for each membrane.

Dye desorption (\%) was also estimated, where dye-saturated membranes were immersed in $50 \mathrm{~mL}$ of $0.01 \mathrm{M} \mathrm{HCl}$ $(\mathrm{pH} 2)$ containing $50 \%$ of EtOH for $1 \mathrm{~h}$ and several replacements until no dye was spectrophotometrycally detected in washing media. Its percentage (\%) was calculated using the following equation:

Desorption $=\frac{C_{A}-C_{D}}{C_{A}} \times 100(\%)$

The membranes reusing in the next cycle of adsorption was estimated by three repetitions for each sample, and the average values as well as the standard deviation of the mean values were calculated.

\section{Filtration Performance}

The membranes' filtration properties (dye removal and flux rate) were evaluated using $5 \mathrm{mg} / \mathrm{L}$ concentrated dye solution. The experiments were performed in dead-end mode using the Sterlitech HP4750 stirred cell filtration system (Sterlitech, Kent, USA). Each membrane, having a diameter of $50 \mathrm{~mm}$, was equilibrated in deionised water for $24 \mathrm{~h}$ before being placed onto a sintered ceramic plate. $100 \mathrm{~mL}$ of dye solution was forced through the membrane with a $0.5 \mathrm{MPa}$ (solvent-casted) or $0.1 \mathrm{MPa}$ (freeze-casted) head pressure under room temperature by simultaneous tracking of filtra-

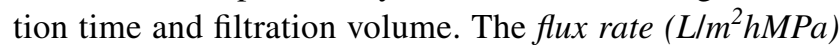
for the active filtration area of $0.002 \mathrm{~m}^{2}$ membrane was calculated. In parallel, dye removal was evaluated from a difference between the starting dye concentration and the concentration of permeate according to Eq. (2) [31]. Up to 4 (for solvent-casted membranes) and 50 (for freeze-casted membranes) filtration cycles were performed for testing the membranes reusing by regenerating them with $100 \mathrm{~mL}$ of $0.01 \mathrm{M} \mathrm{HCl}(\mathrm{pH} 2)$ containing $50 \%$ of $\mathrm{EtOH}$ (the EtOH was used to break hydrophobic interactions being also present). The dye desorption was further calculated according to Eq. (3). Three repetitions of each sample were performed for obtaining statistically meaningful results.

\section{Results and Discussion}

\section{Identification and Evaluation of CA-Mediated Cross-Linking}

The CA-mediated chemistry was introduced for cross-linking of CMC with CNF via available hydroxyl groups, as provisioned on Scheme 1, based on previous studies using cellulose-based substrates [32-35]. FTIR and solid state ${ }^{13} \mathrm{C}$ CP/NMR spectroscopy's, and thermal analyses were performed to identify and evaluate the cross-linking. The thinner membranes prepared from $13.6 \mathrm{~mL}$ of $7 \mathrm{CNF} / 1 \mathrm{CMC}$ and 4CNF/4CMC dispersions were used for this study.

The FTIR spectral data (Fig. 1) of the solvent-casted CNF/CMC membranes demonstrate typical spectral lines for CNF [36], CMC and CA [37]. In brief, band $~ 900 \mathrm{~cm}^{-1}$ (in $\mathrm{CMC}$ and $\mathrm{CNF}$ ) and $1742.3 \mathrm{~cm}^{-1}$ (in anhydrous $\mathrm{CA}$ ) are assigned to ether $(\mathrm{C}-\mathrm{O}-\mathrm{C})$ stretch vibration, the $1000-1070 \mathrm{~cm}^{-1}$ is region of primary $\left(\sim 1030 \mathrm{~cm}^{-1}\right)$ and secondary $\left(\sim 1055 \mathrm{~cm}^{-1}\right)$ alcohols, the $3600-3000 \mathrm{~cm}^{-1}$ is $\mathrm{O}-\mathrm{H}$ vibrations region, etc. Importantly, the IR spectral lines evidence the esterification by the appearance of a peaks at $1719.4 \mathrm{~cm}^{-1}$ and $1727.1 \mathrm{~cm}^{-1}$ in both CNF/ 


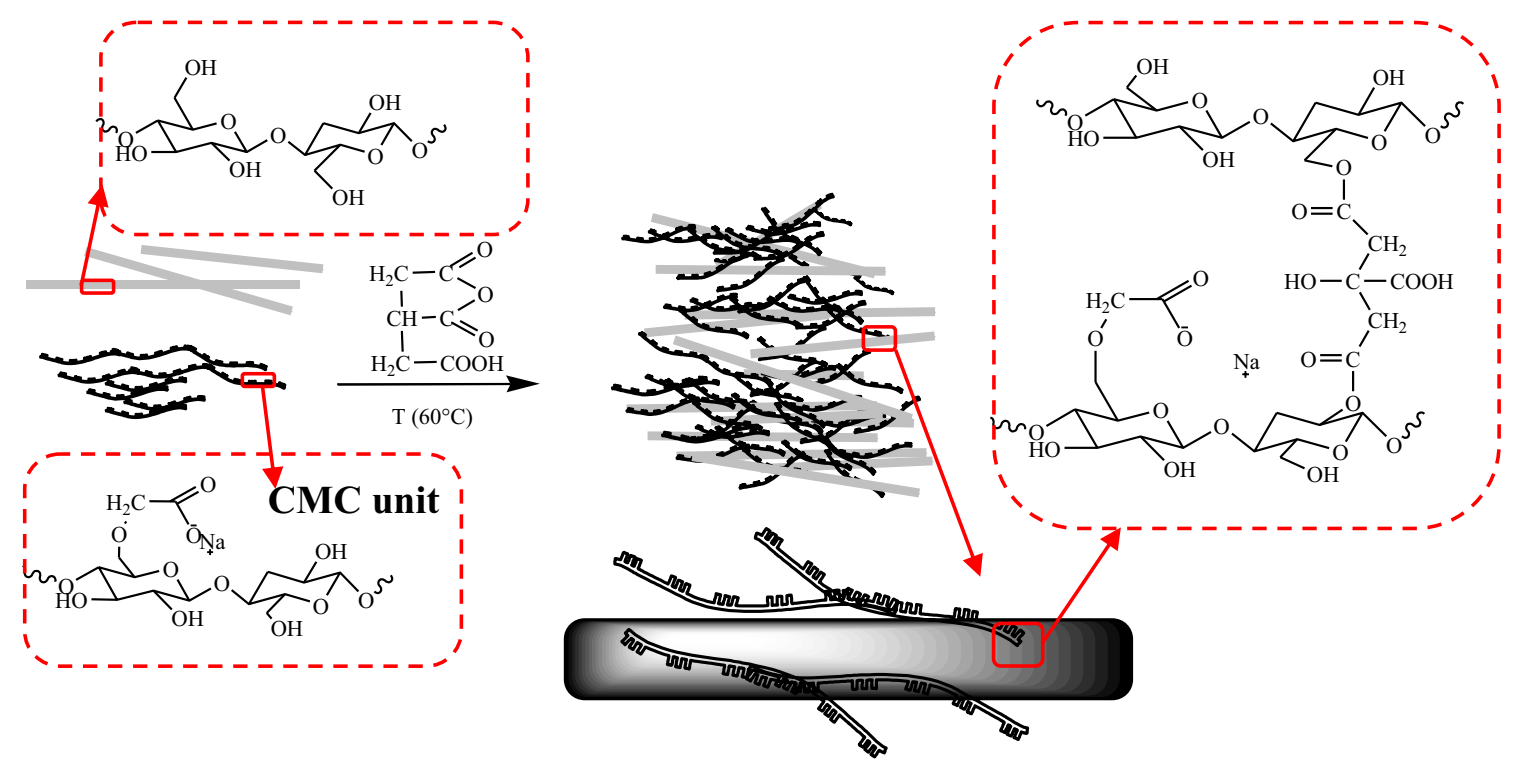

Scheme 1 Tentative mechanism for CA-mediated CMC coupling with CNF. According to [35], the CA anhydride can react with each of three hydroxyl groups in the anhydroglucose monomers, same as with the carbohydrates' reducing ends, resulting in mono-, di- and/or tri esters

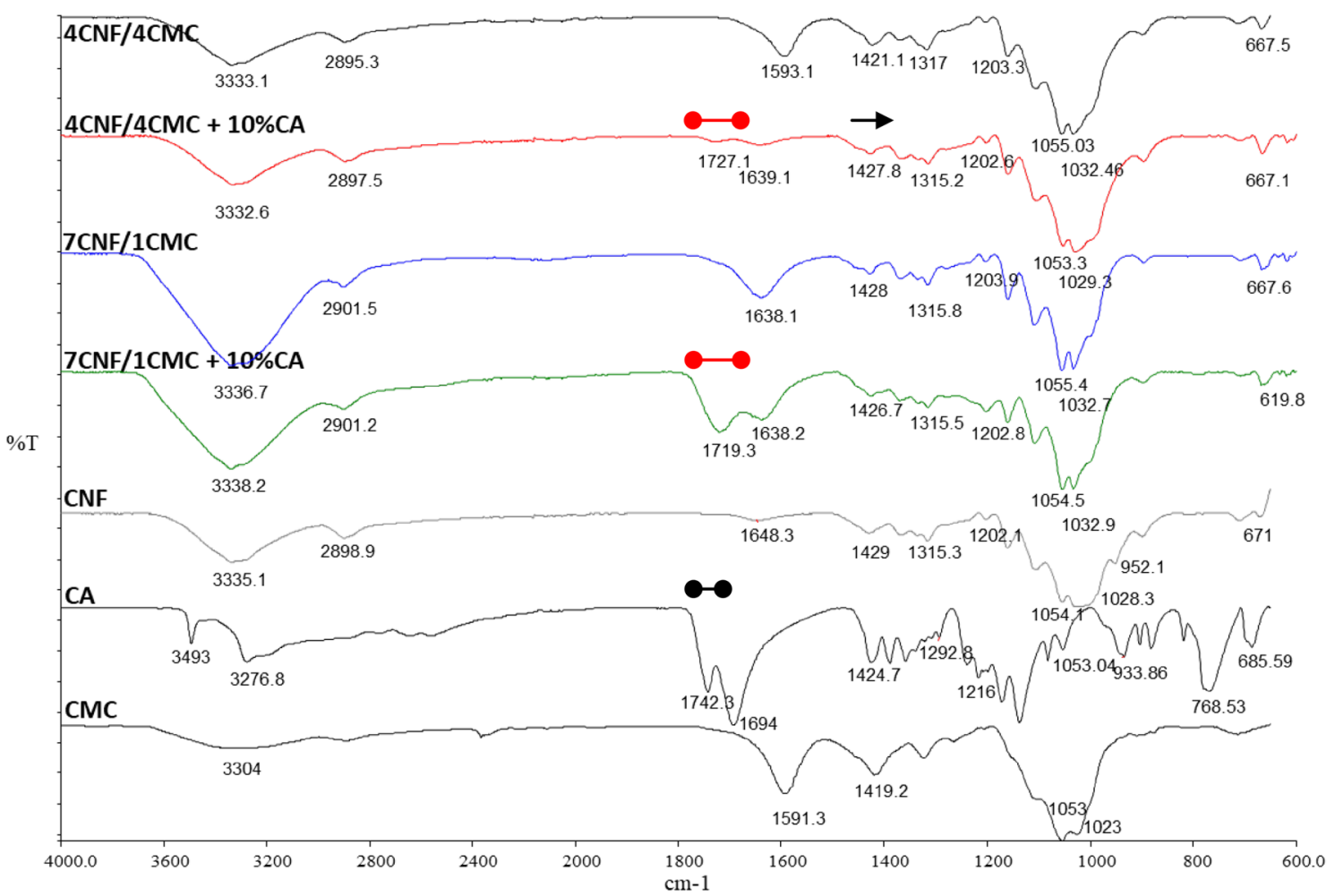

Fig. 1 ATR-FTIR spectra of control powders (CNF, CMC, CA) and CNF/CMC-based membrane, prepared from different components' volume ratios $(4 / 4,7 / 1)$ without and with the addition of $10 \mathrm{wt} \% \mathrm{CA}$ by solvent-casting

CMC membranes prepared with $10 \mathrm{wt} \%$ of CA, respectively, being assigned to the $\mathrm{C}=\mathrm{O}$ ester band [38]. This vibration is missing in $\mathrm{CMC}, \mathrm{CNF}$ and $\mathrm{CA}$ references, as well as CA-free membranes. Indeed, the presence of moisture $(5-20 \%)$ and acid $\mathrm{pH}(\mathrm{pH}<2)$ during processing were found to favour the esterification process [39] even at relatively low temperature $\left(60^{\circ} \mathrm{C}\right)$ at the expense of prolonged reaction time. The coupling process also shift 
the position of CMC-related metoxy group $\left(-\mathrm{O}-\mathrm{CH}_{3}\right)$ vibration for up to $6 \mathrm{~cm}^{-1}$ in 4CNF/4CMC membrane (from 1419.2 to $1427.9 \mathrm{~cm}^{-1}$ ). The ATR-FTIR revealed a very similar profile regarding the FTIR band positions for freeze-casting processed membranes (data not presented), probably due to molecular similarities within macroscopically diverse systems.

The FTIR findings were further supported by solid state ${ }^{13} \mathrm{C} \mathrm{CP/NMR} \mathrm{spectroscopy} \mathrm{(Fig.} \mathrm{2a)} \mathrm{using} \mathrm{the} \mathrm{same} \mathrm{solvent-}$ casted membranes. Both spectra revealing typical cellulosic features: the complex $\mathrm{C} 1$ resonance at $100 \mathrm{ppm}$, two different contributions for $\mathrm{C} 4$ and $\mathrm{C} 6$ signals, related to crystalline (90 ppm and $65 \mathrm{ppm}$ ) and amorphous (84 ppm and $62 \mathrm{ppm}$ ) regions, and unresolved C235 signal near $75 \mathrm{ppm}$. The apparent chemical shift, cantered at $\sim 180 \mathrm{ppm}$ was observed only for those samples being prepared with $10 \mathrm{wt} \%$ of CA, attributing the ester-bonds formation. On the other hand, the CA-related chemical shifts, C3' (73 ppm), C4' ( 44 ppm), and $\mathrm{C} 1 \times 2^{\prime},(175-180 \mathrm{ppm})$, largely contribute to spectral data, later overlapping with the ester resonance region when free CA is not removed from the sample, as can be seen from the $7 \mathrm{CNF} / 1 \mathrm{CMC}$ being prepared with $10 \%$ wt of $\mathrm{CA}$ before washing.
In an attempt to resolve the esterification position on $\mathrm{CNF}$, the de-convoluted spectral lines in the 55-110 ppm region were examined (Fig. 2b), indicating amorphous part reduction due to the disappearance of $\mathrm{C} 4 \mathrm{a}-$ related chemical shift, and consequent crystallinity (CI) increase after the coupling process. In this way, the additional ordering within the sample as a consequence of CA-contribution to inter-molecular H-bonding system was again confirmed. Moreover, the $1.6 \mathrm{ppm}$ shift of C6a towards higher values, and no significant change in the $\mathrm{C} 235$ (coupled) peak may provide additional clues for the involvement of secondary hydroxyl groups (from CNF or CMC) in the chemical reaction. However, the reactive position cannot be confirmed with $100 \%$ accuracy due to possible systematic/mathematical errors which increase in proportion to the extent of peak overlap [40], being characteristic for hydroxyl-rich materials such as ours.

The thermal analyses of the samples were performed as a comparative tool for the identifications of cross-linking effects. The thermograms, presented on Fig. 3, evidenced of $\sim 20^{\circ} \mathrm{C}$ higher degradation temperature $\left(T_{d}\right)$ for all CA-contained samples, which imply on their strengthened molecular structure and consequently improved stability. The CA

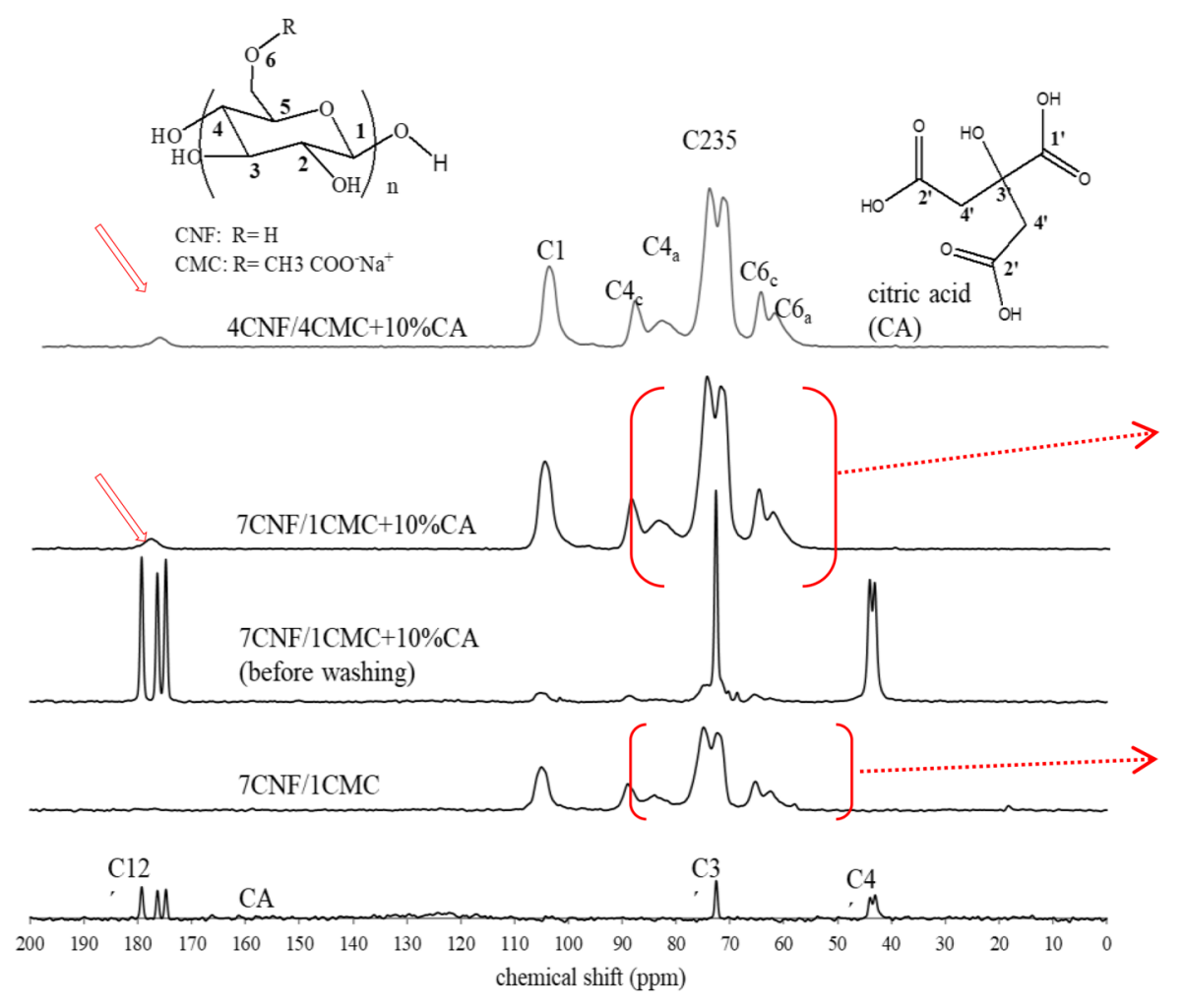

(a)
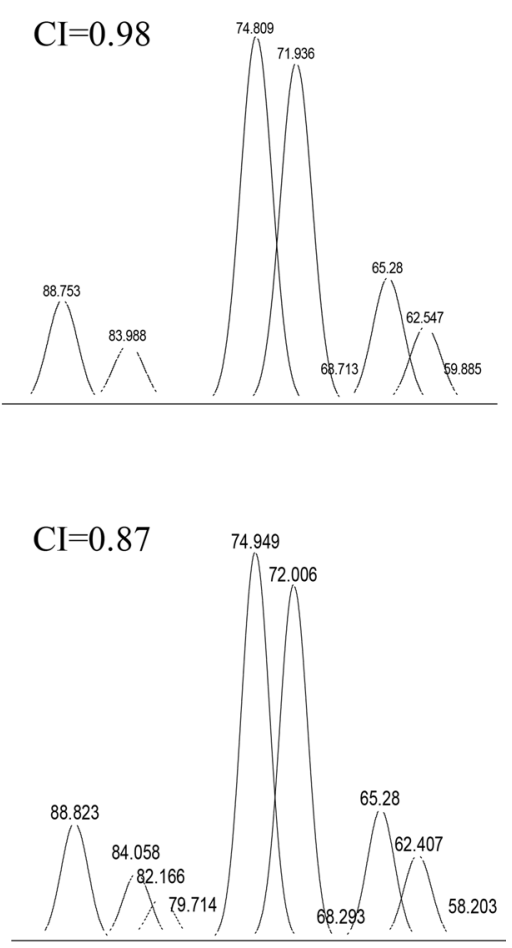

(b)
Fig. 2 Solid-state ${ }^{13} \mathrm{C}$ NMR spectra of CNF/CMC-based membrane, prepared from different components' volume ratios $(4 / 4,7 / 1)$ without and with the addition of $10 \mathrm{wt} \% \mathrm{CA}$ by solvent-casting. Spectra are presented $\mathbf{a}$ before and after washing, and with $\mathbf{b}$ de-convoluted region of interest. Subscripts $a$ and $c$ as present in C4 and C4 peaks are assigned to amorphous and crystalline parts, respectively 
Fig. 3 a DSC and b TGA thermograms of CNF/CMCbased membrane, prepared from different components' volume ratios $(4 / 4,7 / 1)$ without and with the addition of $10 \%$ wt CA by solvent- versus freeze-casted membranes

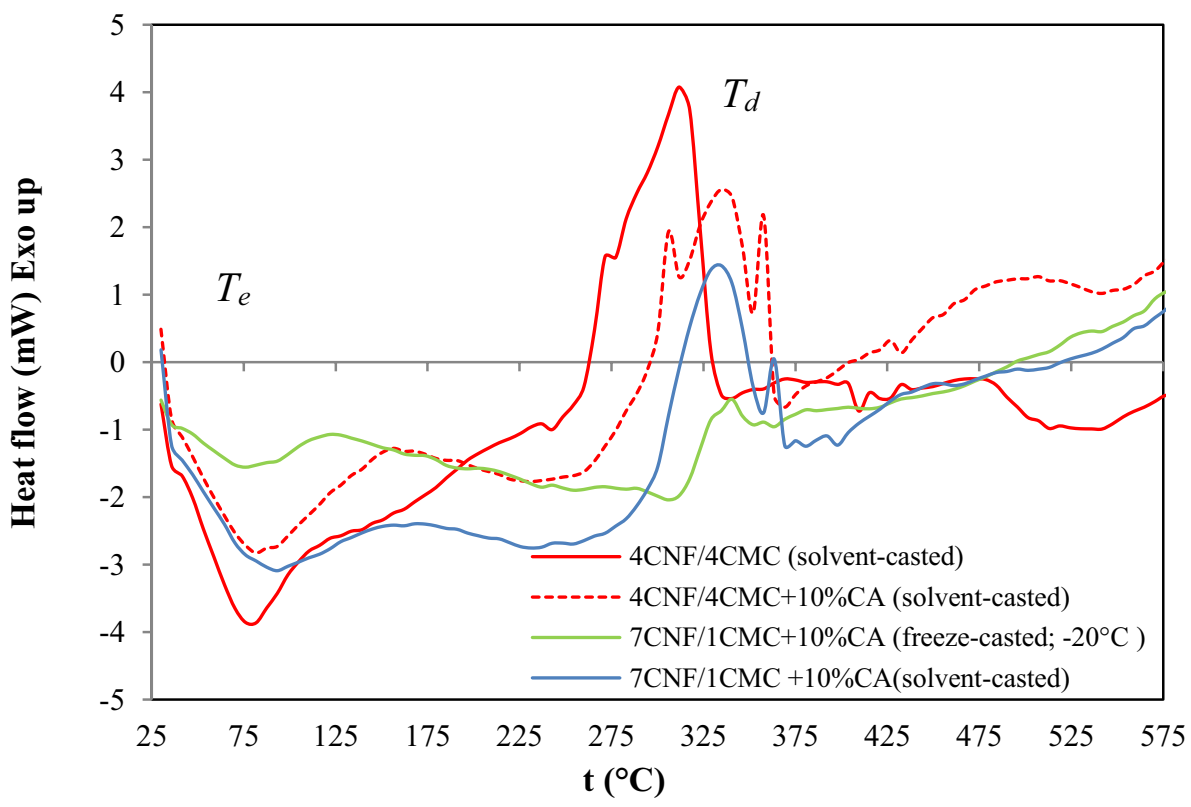

(a)

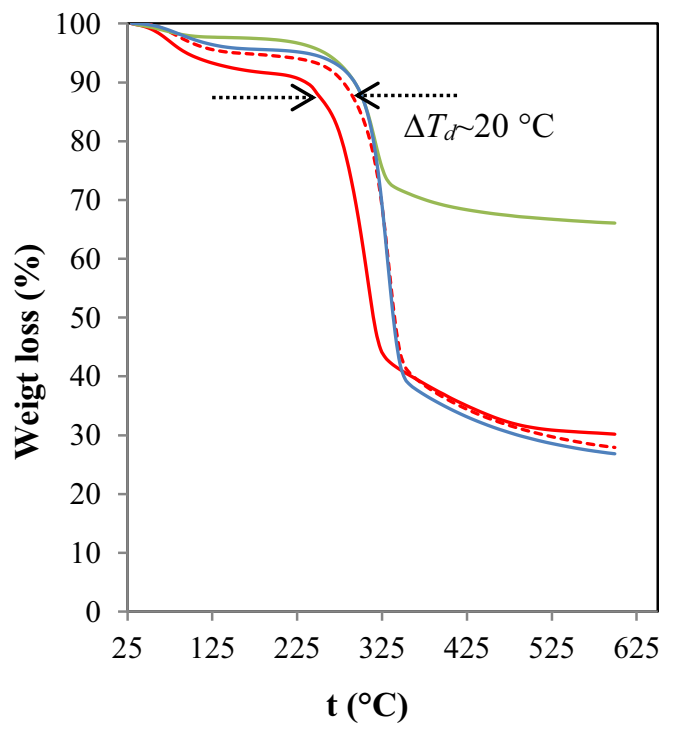

(b)

was not observed as a separate peak at $\sim 480{ }^{\circ} \mathrm{C}$ as found in the literature [41], suggesting on the physicochemical compatibility of CA within the samples and its contribution to intra-molecular $\mathrm{H}$-bonding with a reduction of water evaporation-related endotherm $\left(T_{e}\right.$ is reduced from $8.8 \%$ at $4 \mathrm{CNF} / 4 \mathrm{CMC}$ to $6.2 \%$ at $4 \mathrm{CNF} / 4 \mathrm{CMC}$ of $\mathrm{CA}$-contained samples). Moreover, the relatively broad endotherm within the $45-200{ }^{\circ} \mathrm{C}$ region $(\Delta H=223.5 \mathrm{~J} / \mathrm{g})$, being visible in the CA-free membrane, indicate on the contribution of surfaceexposed CMC-related carboxylic groups [42], being differently oriented when CA is present.

\section{Structure of Membranes}

In order to get more reliable information about membranes' structure, the surface and bulk structure of membranes prepared from different CNF/CMC' volume ratios $(4 / 4,7 / 1,8 / 8$, $14 / 2$ ) as well as CA content ( 5 and $10 \%$ ) were analysed by SEM (in dry-state) as well as by CFM (in wet-state) imaging using RBITC-labelled CNFs.

Non-uniformly dispersed CNFs, forming large bundles and irregular pores, in case of low CMC content (7/1 and 14/2) are depicted within SEM images of solvent-casted 
membrane surfaces (Fig. 3a). Higher CMC presence (4/4 and 8/8) improves the CNF dispersibility whilst reducing the porosity due to the extensive H-bonding and Van der Walls forces, both requiring the molecular contact (hydroxyl groups distance of $0.25-0.35 \mathrm{~nm}$ ) [43], which occurs during the casting process. The CNFs assembling within the membrane thickness can be better seen from CFM images (Fig. 3b), that induce surface folding which intensify proportionally with the CNF content. The membrane shrinking is generated by stress left-over from the lack of complete uniformity in the fibres' distribution. Oppositely, the bottom part containing CNF-rich and densely packed phases is almost identical in all films, as it can be seen by intensive fluorescence scattering at bottom line of yz projectionsprobably due to the CNF setting within a relatively long $(24 \mathrm{~h})$ solvent-casting process. The $4 \mathrm{CNF} / 4 \mathrm{CMC}$-based membrane differ to highest extent among samples by means of frequency and intensity of measured signal $(\max / 13 /$ optical sections were obtained, as well as highest/120 $\mu \mathrm{m} /$ scanning thickness comparing to others), which was hardly visible by SEM (Fig. 4).

On the other hand, the surface and cross-sectional images of unidirectional freeze-casted membranes (Fig. 5) demonstrate the composition-dependent $\mu$-structuring process where the CNF prevalence and higher CA presence evokes the structure compacting. The CNF tendency toward compacting is seen also in a membrane prepared by the same process and using only CNFs, which $\mu$-structure collapse in the case of CA absence or adapt lamellar morphology with aligned sheets by freezing direction when using 10 wt $\% \mathrm{CA}$ as a consequence of CNFs self-assembling phenomena [44]. In addition, a pore size distribution and gradient was observed within the CFM surface and cross-section images. While highly porous, isotropic structuring at top and cross-sections was found in both membranes with higher CMC presence (4/4 and 8/8), an anisotropic and gradient structuring within same sections was found in the CNFprevalent (7/1 and 14/2) membranes, irrespective of precasting volume or the membrane thickness (data are given in Table inserted in Fig. 6). This in turn improves the pore wall thickness (from a few up to $>50 \mu \mathrm{m}$ ) and at the same time allows CNF' orientations within the walls. The CNF and $\mathrm{CMC}$ orientation during the structuring process is an expected phenomenon, being primarily related to the bottom-up directed super-cooling of the water molecules, followed by ice nucleation and propagation [28], which allows
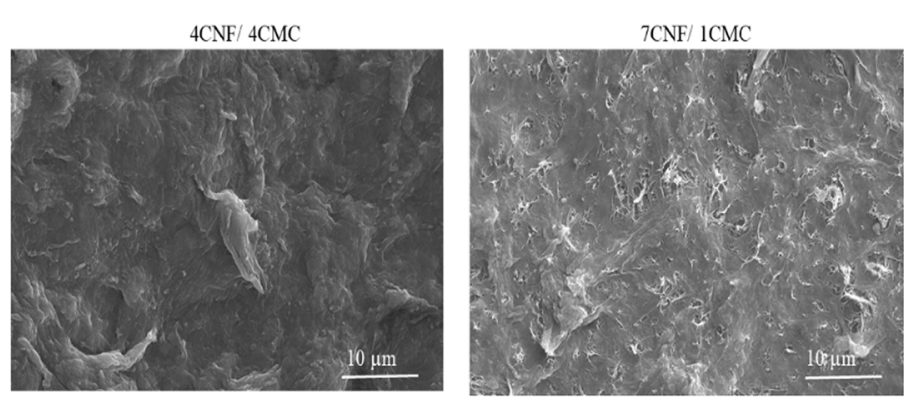

(a)
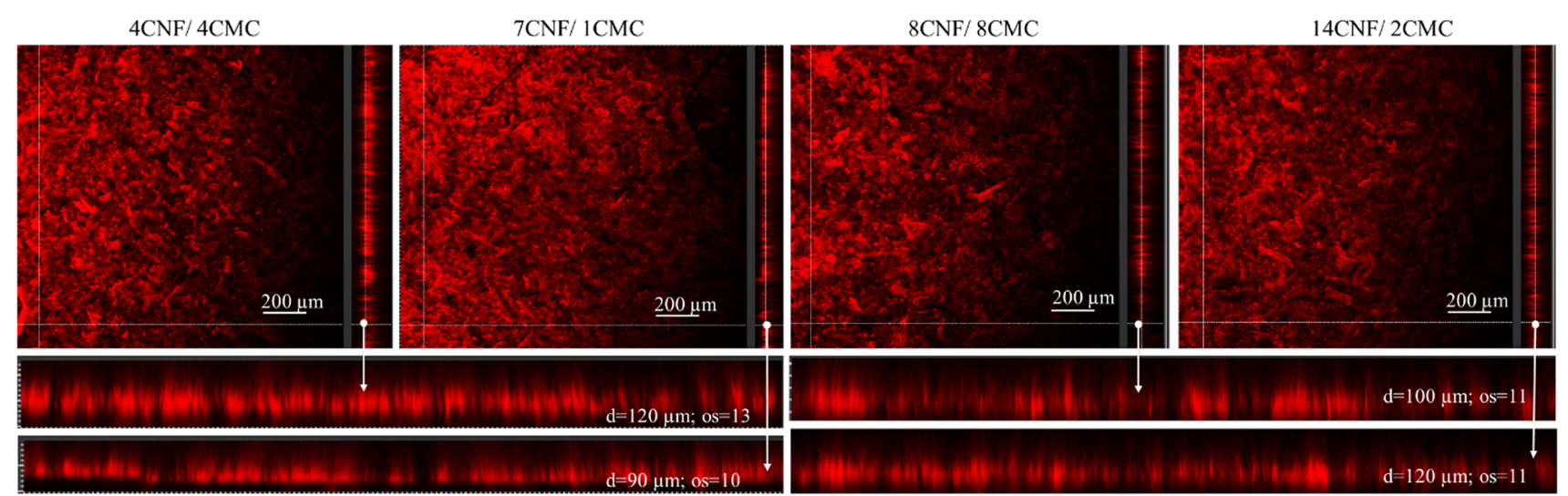

(b)

Fig. 4 a SEM and b CFM images of CNF/CMC-based membranes' surfaces and cross-sections (inserted yz projections), prepared from different components' volume ratios $(4 / 4,7 / 1,8 / 8$ and 14/2) with the addition of $10 \mathrm{wt} \% \mathrm{CA}$, and processed by solvent-casting; inserted yz projections contain stack thickness (d) and number of optical sections (os) 

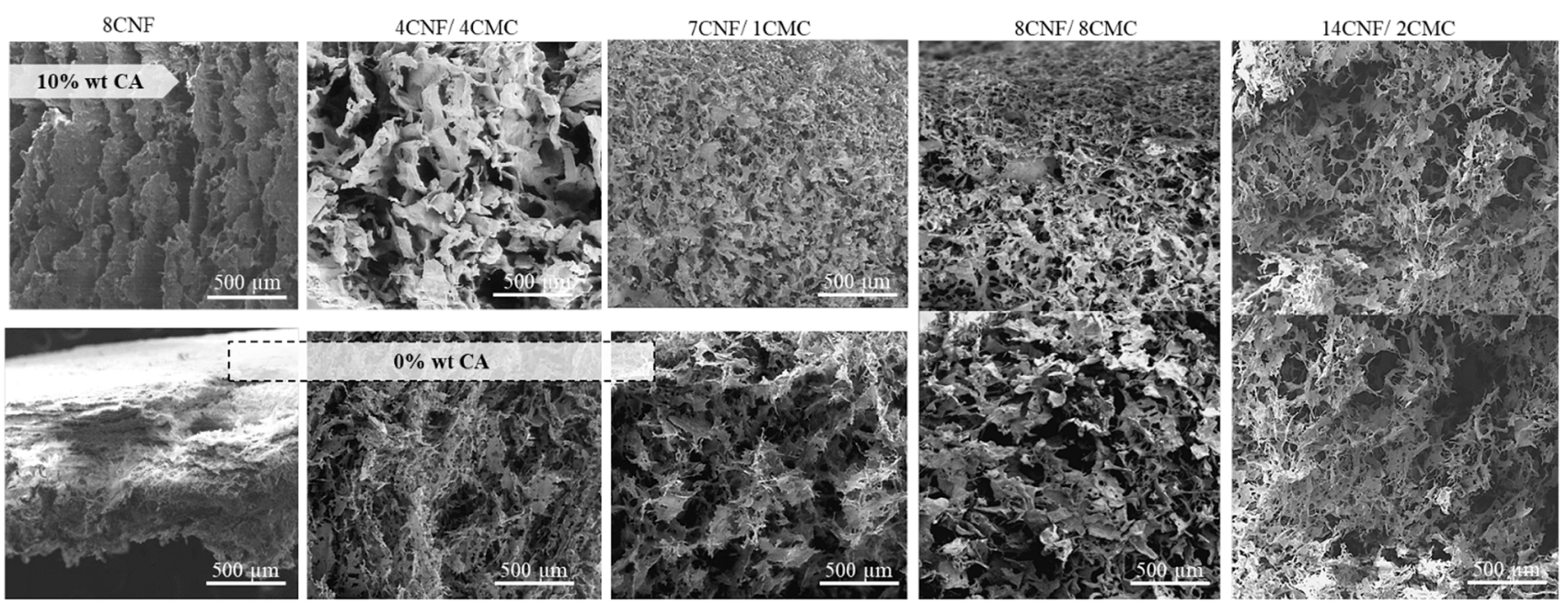

(a)
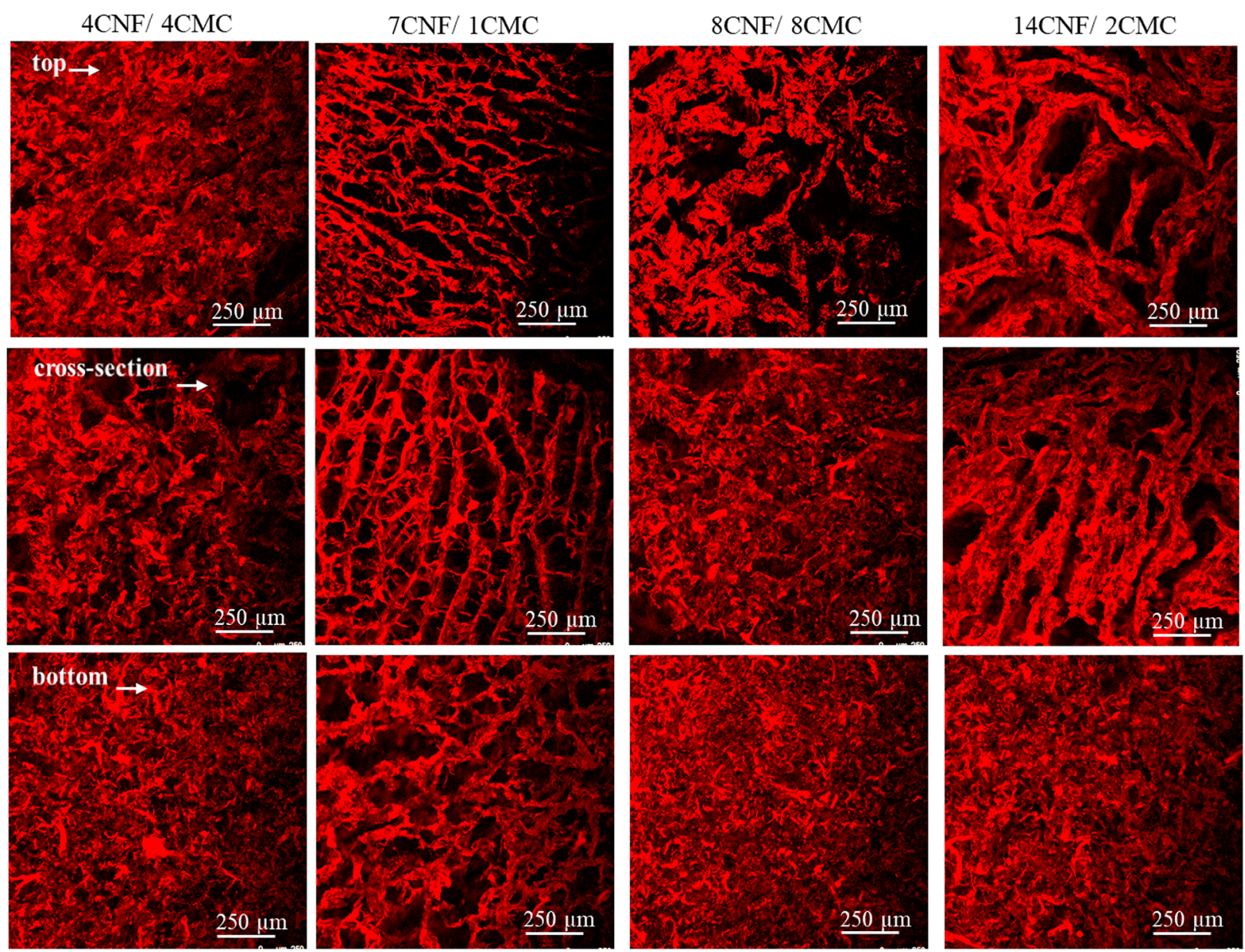

(b)

Fig. 5 a SEM and b CFM images of surface and cross-section of $\mathrm{CNF}$ and $\mathrm{CNF} / \mathrm{CMC}$-based membranes, prepared from different components' volume ratios $(4 / 4,7 / 1,8 / 8$ and $14 / 2)$, without and with the addition of $10 \mathrm{wt} \% \mathrm{CA}$, and processed by unidirectional freeze-casting process. For full thickness presentation of $8 / 8$ and 14/2 monoliths, two merged micrographs are presented 


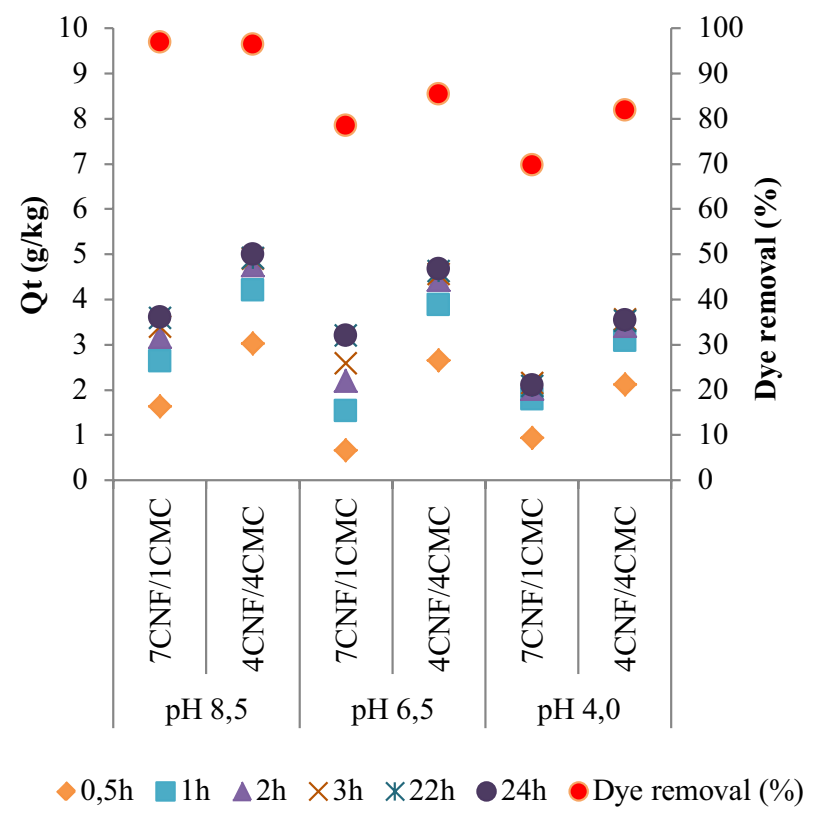

(a)

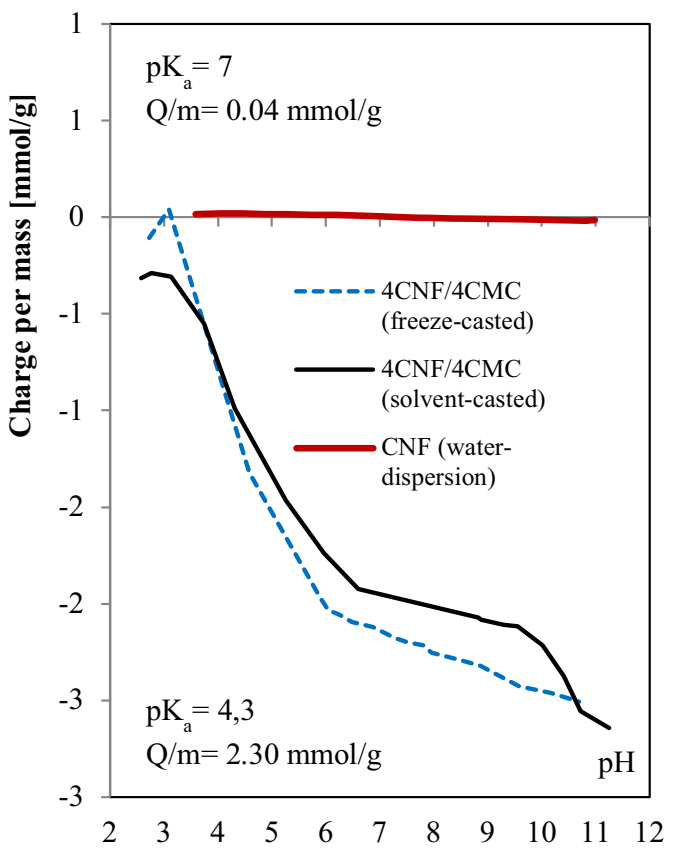

(b)
Fig. 6 a Adsorption capacities of solvent-casted membranes prepared with different $\mathrm{CNF} / \mathrm{CMC}$ ratios $(4 / 4,7 / 1)$ and $10 \mathrm{wt} \%$ of $\mathrm{CA}$ addition, towards BR dye $(5 \mathrm{mg} / \mathrm{L}$ ) dissolved in different $\mathrm{pH}$ mediums ( $\mathrm{pHs} 4$, 6.5 and 8.5$)$ and for different time periods $(0.5-24 \mathrm{~h})$, and percentage

water crystals' growth from the freezing-plate exposed area during the ice propagation to the air-exposed surface area, leaving the pore gradient after ice sublimation. The orientation is also dominated by CNF's size/weight ratio and additionally supported by the CMCs' $\mathrm{pH}$ and ionic strength conformational propensities of both hydrophilic (carboxylated) and hydrophobic (amphipathic anhydrous glucopyranose) units which allow their nano-scale adaption on a particular surface [45]. Due to the negative charges of both, CMC and $\mathrm{CA}$, this molecule aligned on hydrophilic CNF rather than agglomerated, which was expected to positively impact on the ionically-driven cationic dye's adsorption processes. Moreover, the spatially non-uniform structuring (density) differences between the top and bottom sides of these membranes arose from the directional freezing process, being prominent in compositions with higher volume and higher $\mathrm{CNF}$ content (i.e. $14 \mathrm{CNF} / 2 \mathrm{CMC}$ ), whilst the lowering of both causes isotropic structuring being present by elongated ellipsoid-like pores with $\sim 0.25 \times 0.5 \mathrm{~mm}$ dimensions and half-lower dimensions in longitudinal (top) and cross-sectional views, respectively.

High porosity ( $>90 \%$ ) of unidirectional freeze-casted membranes was also identified by $\mathrm{Hg}$ intrusion porosimetry measurements (Fig. 7, inserted table). An exception of dye removal after 24 of immersion. b Potentiometric titration curve of $0.5 \mathrm{wt} \% \mathrm{CNF}$ water-dispersion and 4CNF/4CMC membranes being prepared with $10 \mathrm{wt} \%$ of $\mathrm{CA}$ addition by solvent-casted and freeze-casted processes, respectively

was seen for the 4CNF/4CMC sample, where half lower porosity was measured, which may be a consequence of the $\mathrm{Hg}$ compression effect as a measuring artifact for material with low compression resilience [46], being $~ 16.5 \%$ for this sample (data not presented). Besides, the average pore size in $60-110 \mu \mathrm{m}$ range was measured and variable pore distribution profiles were identified amongst which the $8 \mathrm{CNF} / 8 \mathrm{CMC}$ sample only showed close-to Gaussian pore size distribution with the lowest average pore size, but the highest porosity, probably due to the gradient structure. In contrast, larger pores' domination and more isotropic structures were measured for the remaining samples, as already identified by SEM imaging. However, the expected high specific surface area (due to CNF presence having 50-70 $\mathrm{m}^{2} / \mathrm{g}$, [20]) was not obtained, and CNF domination contributed only slightly to its increase, which may be related to the CNF assembling [47], being also seen from CFM images, having $\mu$-rather than nano-scale dimensions [48]. A similar trend was observed by BET analyses of the solvent-casted membranes (e.g. 7CNF/1CMC prepared with $10 \%$ wt CA having $2.53 \mathrm{~m}^{2} / \mathrm{g}$ ), which confirm the compositional rather than structuring/porosity influence onto specific surface areas, however with more than three logs lower porosity (50 $\mathrm{nm}$ vs. $60-100 \mu \mathrm{m})$. 


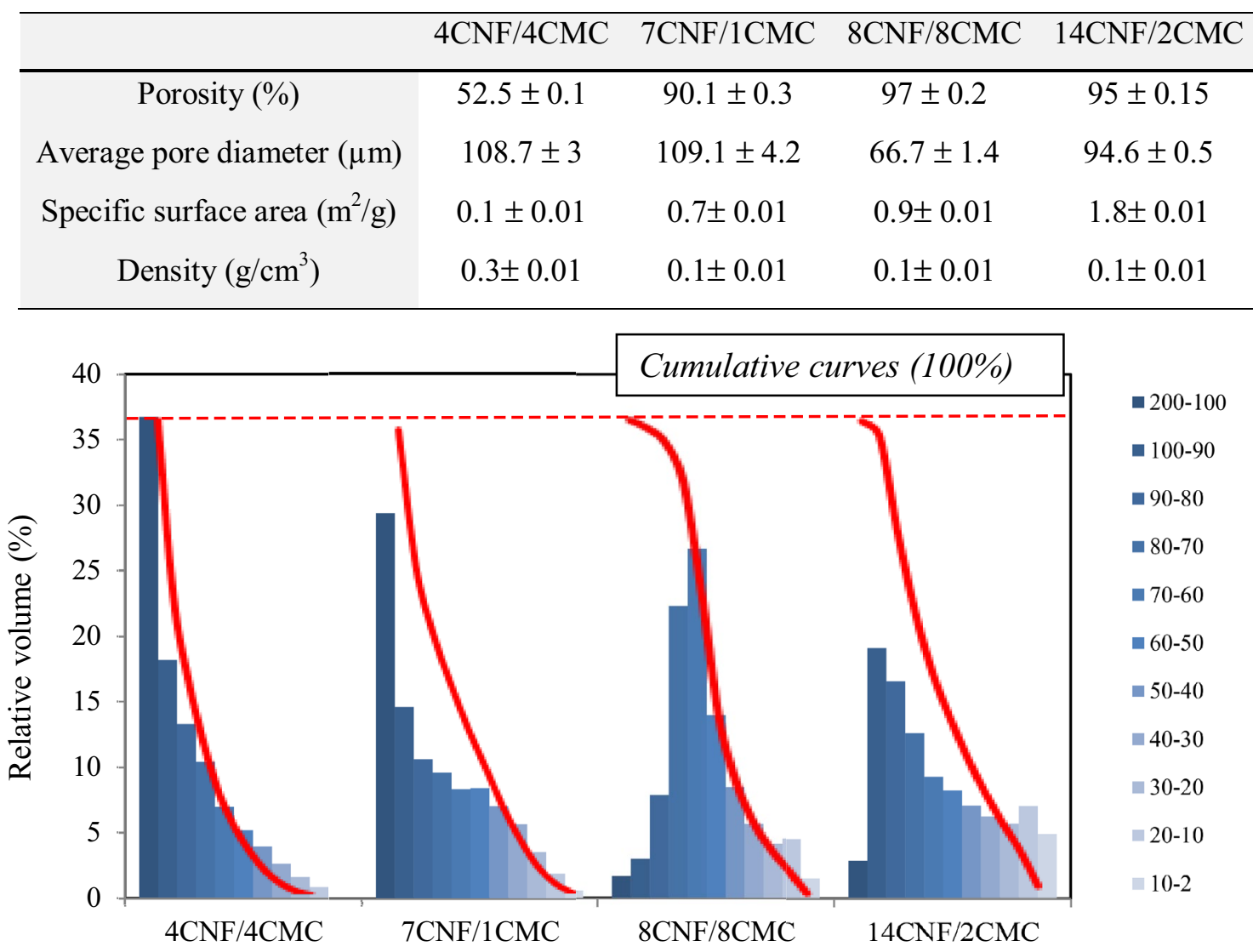

Fig. 7 Mercury porosimetry data of CNF/CMC-based membranes, prepared from different CNF/CMC volume ratios (4/4, 7/1, 8/8 and/or 14/2) with the addition of $5 \mathrm{wt} \% \mathrm{CA}$ by unidirectional freeze-casting process

\section{Adsorption Capacity, Kinetic and Desorption}

The solvent $\mathrm{pH}^{\prime}$ determines the adsorbate (dye) ionization, the adsorbent (membrane) surface charge [11], as well as the structure of dye molecule [49]. Accordingly, the adsorption capacity of all membranes against two selected dyes was assessed at different $\mathrm{pHs}(4 ; 6.5$ and 8.5$)$ in respect to their $\mathrm{pKa}$ values ( $\mathrm{pKa}<1$ and 6.13 for MB and BR, respectively) by utilizing the same initial dye concentration $(5 \mathrm{mg} / \mathrm{L})$ and using batch equilibrium experiment.

The obtained results of solvent-casted membranes (Fig. 6a) indicate a straight-forward relation between dye adsorption capacity and solution' $\mathrm{pH}$, which, together with $30 \%$ higher adsorption of membranes with higher CMC content disclose the CMCs-driven adsorption process [50]. Moreover, the adsorption kinetic is the fastest at lowest $\mathrm{pH}$ incubation, which may be the consequence of the dye diffusion rate rather than the membrane surface effect [51]. In addition, the selected (4CNF/4CMC) membranes' polynomial titration curves (Fig. 6b) support their $\mathrm{pH}$-dependent action, bringing a (fast irrespective of the preparation processing) total negative charge of $\sim 2.3 \mathrm{mmol} / \mathrm{g}$, implying a major contribution of carboxylic groups ( $\mathrm{pKa}$ at $\mathrm{pH}$ 4.3) from $\mathrm{CMC}$ and an insignificant one from $\mathrm{CNF}$ $(\sim 0.04 \mathrm{mmol} / \mathrm{g})$. Accordingly, the $4 \mathrm{CNF} / 4 \mathrm{CMC}$ membrane should accommodate $\sim 660 \mathrm{~g}$ of $\mathrm{MB}$ or $\sim 1021 \mathrm{~g}$ of BR on $1 \mathrm{~kg}$ of membrane, values being in the range of those obtained by the adsorption kinetic modelling, collected in Table 1. Differences between these values rely on the other forces that are also involved in a dye adsorption, such as $\mathrm{H}$-bonding (being present above all between $-\mathrm{OH}$ groups and $-\mathrm{N}$ atoms) as macro-to-nano scales dominant forces within cellulose [52], which together with permselective function to substances with different charge properties [53] may explain the random adsorption capacity of both dyes across different compositions and preparation procedures.

The higher adsorption capacities of solvent-casted over the freeze-casted membranes at the same starting dye concentrations are probably due to the better accessibility of a highly adsorptive CMC-rich phase. Indeed, in the case of freeze-casted membranes, the CNF-related compacting effect within the pore walls (being identified by CFM) was inhibits the adsorption. Such a phenomena have been already observed for the adsorption of different dyes onto biomass, coir pith carbon and perlite [49]. 
Table 1 Thicknesses and kinetic parameters (Qe, $\mathrm{k}$ and $\mathrm{R}^{2}$ ) (data obtained from linear curve-fitted pseudo-second order kinetic plots) for solvent-casted and freeze-casted membranes prepared with differ-

\begin{tabular}{|c|c|c|c|c|c|c|c|c|c|}
\hline \multirow[t]{2}{*}{ Dye } & \multirow[t]{2}{*}{ Membrane } & \multicolumn{4}{|l|}{ Solvent-casted } & \multicolumn{4}{|l|}{ Freeze-casted } \\
\hline & & Thickness (mm) & Qe $(\mathrm{g} / \mathrm{kg})$ & $\mathrm{k}(\mathrm{kg} / \mathrm{g}$ min $)$ & $\mathrm{R}^{2}$ & Thickness (mm) & Qe $(\mathrm{g} / \mathrm{kg})$ & $\mathrm{k}(\mathrm{kg} / \mathrm{g} \min )$ & $\mathrm{R}^{2}$ \\
\hline \multirow[t]{4}{*}{$\mathrm{MB}$} & 4CNF/4CMC & $0.12 \pm 0.01$ & 9.4 & 0.42 & 0.999 & $5.3 \pm 0.1$ & 1828.5 & 0.42 & 0.994 \\
\hline & 7CNF/1CMC & $0.12 \pm 0.01$ & 17.5 & 0.83 & 0.999 & $5.2 \pm 0.1$ & 1398.7 & 0.83 & 0.981 \\
\hline & 8CNF/8CMC & $0.24 \pm 0.02$ & 20.1 & 0.21 & 0.999 & $9.4 \pm 0.3$ & 778.3 & 0.21 & 0.940 \\
\hline & $14 \mathrm{CNF} / 2 \mathrm{CMC}$ & $0.24 \pm 0.02$ & 39.8 & 0.21 & 0.999 & $10.3 \pm 0.1$ & 586.9 & 0.21 & 0.976 \\
\hline \multirow[t]{4}{*}{$\mathrm{BR}$} & 4CNF/4CMC & $0.12 \pm 0.01$ & 1.9 & 0.22 & 0.999 & $5.3 \pm 0.1$ & 8.9 & 0.61 & 0.999 \\
\hline & 7CNF/1CMC & $0.12 \pm 0.01$ & 6.4 & 0.24 & 0.999 & $5.2 \pm 0.1$ & 30.3 & 0.54 & 0.999 \\
\hline & 8CNF/8CMC & $0.24 \pm 0.02$ & 98.2 & 1.73 & 0.988 & $9.4 \pm 0.3$ & 81.9 & 1.02 & 0.998 \\
\hline & $14 \mathrm{CNF} / 2 \mathrm{CMC}$ & $0.24 \pm 0.02$ & 225.6 & 3.52 & 0.998 & $10.3 \pm 0.1$ & 22.5 & 1.08 & 0.999 \\
\hline
\end{tabular}

ent CNF/CMC ratios (4/4, 7/1, 8/8 and/or 14/2) and $10 \mathrm{wt} \%$ of CA addition towards $\mathrm{MB}$ and $\mathrm{BR}$ dyes $(5 \mathrm{mg} / \mathrm{L})$ at $\mathrm{pH} 8.5$ after $24 \mathrm{~h}$
To understand and compare the dynamics of the adsorption process, the pseudo-second-order kinetic model was applied giving the linear fit in $24 \mathrm{~h}$ contact time. From the obtained parameters ( $k$ and $Q e$ ), both the composition and structuring-dependent adsorption process can be outlined. Indeed, a freeze-casted, fully isotropic 4CNF/4CMC membrane demonstrate faster MB adsorption $(\sim 8.5 \mathrm{~kg} / \mathrm{g}$ $\mathrm{min}$ ) over the anisotropic 7CNF/1CMC ( $\sim 5.4 \mathrm{~kg} / \mathrm{g} \mathrm{min})$, as well as significantly higher adsorption capacity at equilibrium ( $\sim 1828 \mathrm{~g} / \mathrm{kg}$ vs. $\sim 1398 \mathrm{~g} / \mathrm{kg}$ ), both over performing the thicker $(\sim 10.3 \mathrm{~mm}$ vs. $\sim 5.25 \mathrm{~mm})$ freeze-casted $14 \mathrm{CNF} / 2 \mathrm{CMC}$ membrane $(\sim 587 \mathrm{~g} / \mathrm{kg})$ and the solventcasted (being below the significance limit). To the best of our knowledge, such dye adsorption capacities, exceeding even those of commercial activated carbons [54], as well as other bio-based absorbers with up to $50 \mathrm{~g} / \mathrm{kg}$ adsorption or even many other non-bio adsorbents $[1,10,55]$ has not been presented yet in the literature.

\section{Filtration Performance of Membranes}

In real-time water treatment processes, the relatively high and stable flux rate with concurrently high dye removal capacity is major determinants for membrane efficiencies. In this respect, the filtration behaviour of differently prepared membranes was investigated using the dead-end cell system and BR of $5 \mathrm{mg} / \mathrm{L}$ at $\mathrm{pH} 8.5$ as a model dye solution. The results presented in Fig. 8 demonstrate $\sim 100 \%$ BR dye removal but relatively low flux rate (up to $20 \mathrm{~L} / \mathrm{m}^{2} \mathrm{~h} \mathrm{MPa}$ ). On the other hand, extremely high (5-logs higher) and compositions irrespective flux rates were measured for freezecasted membranes, keeping ultra high ( 99\%) dye removal capacity for thicker and CMC-rich sample (8CNF/8CMC), being $~ 12.6 \%$ lower for CNF-rich (14CNF/2CMC) and $\sim 24 \%$ and $\sim 34 \%$ lower for thinner samples (4CNF/4CMC and $7 \mathrm{CNF} / 1 \mathrm{CMC}$, respectively). Indeed, the anisotropic, open pore structure and the missing of unidirectional pore channels [56] (as demonstrated by SEM and CFM imaging) in combination with charged (CMC-rich) walls improves the adsorption of dye molecules, being efficiently removed by simple irreversible flashing of membranes with $50 \% \mathrm{EtOH}$ of $\mathrm{pH} 2$.

In order to imply the reuse potentials of membranes [57], dye desorption capacity was thus also quantified, indicating very high values in all cases $(>95 \%)$, which arise from the dye-membrane H-bonding, ionic and hydrophobic interactions being pronounced at low $\mathrm{pH}$ and with EtOH presence [53]. Moreover, the intensive flux declination within 8CNF/8CMC of solvent-casted membrane (down to 0 ) was observed already after 4 filtration cycles using BR, which omits the continuation of experiment. On the other hand, the 50 filtration cycles was performed by using freeze-casted membrane of the same composition without flux declination and still relatively high dye adsorption percentage (from $99 \%$ at 1 st to $90 \%$ at 50th cycle). In addition, the SEM images of this membrane, obtained before and after filtration cycles, demonstrated it's high compacting, without significantly affecting on its bulk structure, proving its high performance.

\section{Conclusion}

Highly efficient and water-resistant biobased membranes were prepared from CMC acting as a dye adsorbent and CNFs as stabilizing and structural filler by using a CAmediated cross-linking chemistry, occurred in situ during the solvent- and unidirectional freeze-casting process, respectively. The membranes were fully characterized by spectroscopic, microscopic, calorimetric/thermogravimetric and potentiometric titration studies, revealed the formation of different surface and bulk structures being governed by the volume ratio of $\mathrm{CNF} / \mathrm{CMC}$, CA addition and fabrication process, and further evaluated for cationic dyes removal capacity and kinetic by batch and dead-end 


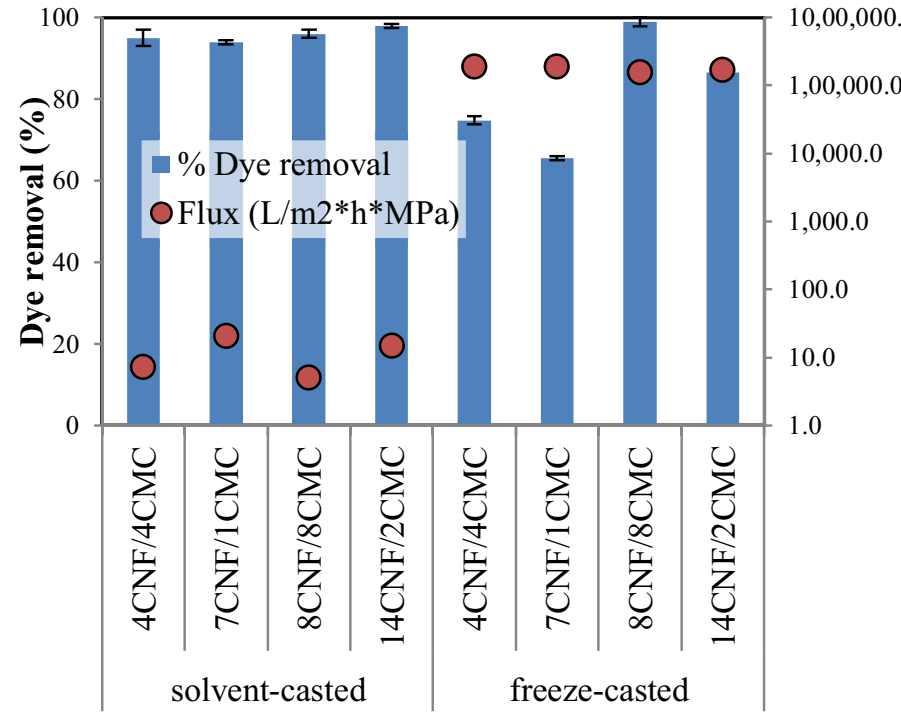

(a)

Fig. 8 a Filtration performance (flux rate and $100 \mathrm{~mL}$ of $5 \mathrm{mg} / \mathrm{L} \mathrm{BR}$ dye removal at $\mathrm{pH}$ 8.5) of membranes prepared with different $\mathrm{CNF} /$ CMC ratios (4/4, 7/1, 8/8 and/or 14/2) and 10\% wt of CA addition by solvent-casting and freeze-casting processes. b Photographs of $8 \mathrm{CNF} / 8 \mathrm{CMC}$ (i) solvent- and (ii) freeze-casted membranes before

filtration modes. The freeze-casting process was found to generate iso- (in equal v/v ratios) or anisotropic (in CNFprevalence) and highly porous membranes which support extremely high flux rates and demonstrate remarkable cationic dye adsorption capacity, providing high-tech performance in adsorption-efficient dead-end filtration technologies as well as reusing ability without a need for additional separation step. Oppositely, dense and film-like membranes, being formed by the solvent-casting process, provide similar adsorption capacities at much lower and time-declining flux rate, demonstrating their potential in spiral wound-cross-flow modules where dye removal capacity provided by functional surface is efficiency determinant. The dye adsorption capacities obtained by these type of membranes are exceeding those of commercial activated carbons as well as other bio-based and non-bio adsorbents that have been presented in the literature, thus showing high application potential.

Acknowledgements The authors greatly acknowledge the co-funding provided by EU FP7 (Project NanoSelect, Grant No. 280519) and Slovenian Research Agency (Project Grant No. L2-7576).
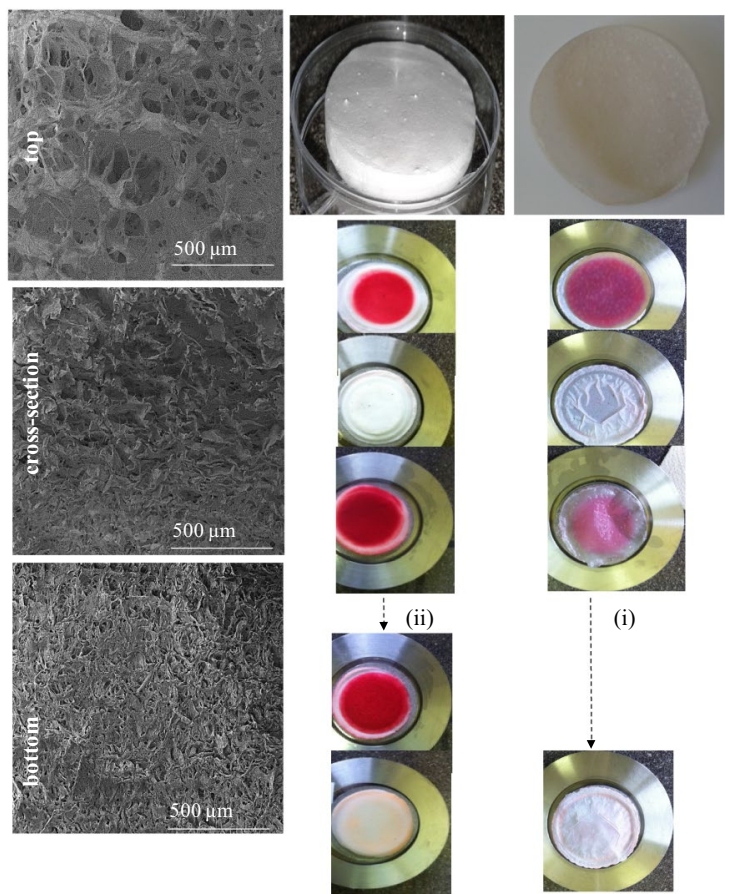

(b)

and after 4th and 50th filtration and regeneration cycle (using $100 \mathrm{~mL}$ of $5 \mathrm{mg} / \mathrm{L} \mathrm{BR}$ dye at $\mathrm{pH} 8.5$ and $50 \% \mathrm{EtOH}$ of $\mathrm{pH} 2$ ), respectively. SEM images of (ii) freeze-casted membrane after 50th filtration cycles are presented on left

Open Access This article is distributed under the terms of the Creative Commons Attribution 4.0 International License (http://creativeco mmons.org/licenses/by/4.0/), which permits unrestricted use, distribution, and reproduction in any medium, provided you give appropriate credit to the original author(s) and the source, provide a link to the Creative Commons license, and indicate if changes were made.

\section{References}

1. Kyzas G, Fu J, Matis K (2013) The change from past to future for adsorbent materials in treatment of dyeing wastewaters. Materials (Basel) 6(11):5131-5158

2. Banat F, Al-Bastaki N (2004) Treating dye wastewater by an integrated process of adsorption using activated carbon and ultrafiltration. Desalination 170(1):69-75

3. Zheng L, Su Y, Wang L, Jiang Z (2009) Adsorption and recovery of methylene blue from aqueous solution through ultrafiltration technique. Sep Purif Technol 68(2):244-249

4. He Y et al (2009) Experimental study on the rejection of salt and dye with cellulose acetate nanofiltration membrane. J Taiwan Inst Chem Eng 40(3):289-295

5. Khouni I, Marrot B, Moulin P, Ben Amar R (2011) Decolourization of the reconstituted textile effluent by different process 
treatments: enzymatic catalysis, coagulation/flocculation and nanofiltration processes. Desalination 268(1-3):27-37

6. Van der Bruggen B (2001) Mechanisms of retention and flux decline for the nanofiltration of dye baths from the textile industry. Sep Purif Technol 22-23(1-2):519-528

7. Schideman LC, Mariñas BJ, Snoeyink VL, Qi S, Campos C (2007) Three-component adsorption modeling to evaluate and improve integrated sorption-membrane processes. Environ Sci Technol 41(18):6547-6553

8. Zahrim AY, Tizaoui C, Hilal N (2011) Coagulation with polymers for nanofiltration pre-treatment of highly concentrated dyes: a review. Desalination 266(1-3):1-16

9. Matsui Y, Colas F, Yuasa A (2001) Removal of a synthetic organic chemical by PAC-UF systems. II: model application. Water Res 35(2):464-470

10. Yagub MT, Sen TK, Afroze S, Ang HM (2014) Dye and its removal from aqueous solution by adsorption: a review. Adv Colloid Interface Sci 209:172-84

11. Sun D, Zhang Z, Wang M, Wu Y (2013) Adsorption of reactive dyes on activated carbon developed from Enteromorpha prolifera. Am J Anal Chem 04(07):17-26

12. Tan IAW, Ahmad AL, Hameed BH (2008) Adsorption of basic dye on high-surface-area activated carbon prepared from coconut husk: equilibrium, kinetic and thermodynamic studies. J Hazard Mater 154(1-3):337-46

13. Campinas M, Rosa MJ (2010) Assessing PAC contribution to the NOM fouling control in PAC/UF systems. Water Res 44(5):1636-1644

14. Sehaqui H, Zhou Q, Ikkala O, Berglund LA (2011) Strong and tough cellulose nanopaper with high specific surface area and porosity. Biomacromolecules 12(10):3638-3644

15. Zhao J, Lu C, He X, Zhang X, Zhang W, Zhang X (2015) Polyethylenimine-grafted cellulose nanofibril aerogels as versatile vehicles for drug delivery. ACS Appl Mater Interfaces 7:2607-2615

16. Xie K, Zhao W, He X (2011) Adsorption properties of nano-cellulose hybrid containing polyhedral oligomeric silsesquioxane and removal of reactive dyes from aqueous solution. Carbohydr Polym 83(4):1516-1520

17. Jiang F, Hsieh Y-L (2013) Chemically and mechanically isolated nanocellulose and their self-assembled structures. Carbohydr Polym 95(1):32-40

18. Eichhorn SJ et al (2009) Review: current international research into cellulose nanofibres and nanocomposites. J Mater Sci 45(1): $1-33$

19. Blaker JJ, Lee K-Y, Bismarck A (2011) Hierarchical composites made entirely from renewable resources. J. Biobased Mater Bioenergy 5(1):1-16

20. Missoum K, Belgacem M, Bras J (2013) Nanofibrillated cellulose surface modification: a review. Materials (Basel) 6(5):1745-1766

21. Eyley S, Thielemans W (2014) Surface modification of cellulose nanocrystals. Nanoscale 6(14):7764-7779

22. Islam MT, Alam MM, Zoccola M (2013) Review on modification of nanocellulose for application in composites. Int J Innov Res Sci Eng Technol 2(10):5444-5451

23. Kumar SK, Jouault N, Benicewicz B, Neely T (2013) Nanocomposites with polymer grafted nanoparticles. Macromolecules 46(9):3199-3214

24. Chen $\mathrm{W}$ et al (2014) Comparative study of aerogels obtained from differently prepared nanocellulose fibers. ChemSusChem 7(1):154-161

25. Karim Z, Mathew AP, Grahn M, Mouzon J, Oksman K (2014) Nanoporous membranes with cellulose nanocrystals as functional entity in chitosan: removal of dyes from water. Carbohydr Polym 112:668-676

26. Gopakumar DA, Manna S, Pasquini D, Thomas S, Grohens Y (2018) Nanocellulose: extraction and application as a sustainable material for wastewater purification. New Polym Nanocompos Environ Remediat. https://doi.org/10.1016/B978-0-12-81103 3-1.00019-6

27. Bao Y, Ma J, Li N (2011) Synthesis and swelling behaviors of sodium carboxymethyl cellulose-g-poly(AA-co-AM-co-AMPS)/ MMT superabsorbent hydrogel. Carbohydr Polym 84(1):76-82

28. Salas C, Nypelö T, Rodriguez-Abreu C, Carrillo C, Rojas OJ (2014) Nanocellulose properties and applications in colloids and interfaces. Curr Opin Colloid Interface Sci 19(5):383-396

29. Sehaqui H, Zimmermann T, Tingaut P (2013) Hydrophobic cellulose nanopaper through a mild esterification procedure. Cellulose 21(1):367-382

30. Park S, Baker JO, Himmel ME, Parilla PA, Johnson DK (2010) Cellulose crystallinity index: measurement techniques and their impact on interpreting cellulase performance. Biotechnol Biofuels $3: 10$

31. Wang Z, Ma H, Hsiao BS, Chu B (2014) Nanofibrous ultrafiltration membranes containing cross-linked poly(ethylene glycol) and cellulose nanofiber composite barrier layer. Polymer (Guildf) 55(1):366-372

32. Kalia $\mathrm{S}$ et al (2011) Cellulose-based bio- and nanocomposites: a review. Int J Polym Sci 2011:1-35

33. Reddy N, Yang Y (2010) Citric acid cross-linking of starch films. Food Chem 118(3):702-711

34. Shi R et al (2008) The effect of citric acid on the structural properties and cytotoxicity of the polyvinyl alcohol/starch films when molding at high temperature. Carbohydr Polym 74(4):763-770

35. Feng X, Xiao Z, Sui S, Wang Q, Xie Y (2014) Esterification of wood with citric acid: the catalytic effects of sodium hypophosphite (SHP). Holzforschung 68(4):427-433

36. Gorgieva S, Girandon L, Kokol V (2017) Mineralization potential of cellulose-nanofibrils reinforced gelatine scaffolds for promoted calcium deposition by mesenchymal stem cells. Mater Sci Eng C 73:478-489

37. Gorgieva S, Kokol V (2011) Synthesis and application of new temperature-responsive hydrogels based on carboxymethyl and hydroxyethyl cellulose derivatives for the functional finishing of cotton knitwear. Carbohydr Polym 85(3):664-673

38. Raucci MG et al (2015) Effect of citric acid crosslinking cellulosebased hydrogels on osteogenic differentiation. J Biomed Mater Res A 103(6):2045-2056

39. Pantze A, Studies of ester formation on a cellulose matrix. Lulel tekniska universitet, Skellefteå

40. Corbett RJT (1993) How to perform automated curve fitting toin vivo 31P magnetic resonance spectroscopic data. MAGMA Magn Reson Mater Phys Biol Med 1(2):65-76

41. Wyrzykowski D, Hebanowska E, Nowak-Wiczk G, Makowski M, Chmurzyński L (2010) Thermal behaviour of citric acid and isomeric aconitic acids. J Therm Anal Calorim 104(2):731-735

42. Fukuzumi H, Saito T, Okita Y, Isogai A (2010) Thermal stabilization of TEMPO-oxidized cellulose. Polym Degrad Stab 95(9):1502-1508

43. Peng Y, Gardner DJ, Han Y (2011) Drying cellulose nanofibrils: in search of a suitable method. Cellulose 19(1):91-102

44. Han J, Zhou C, Wu Y, Liu F, Wu Q (2013) Self-assembling behavior of cellulose nanoparticles during freeze-drying: effect of suspension concentration, particle size, crystal structure, and surface charge. Biomacromolecules 14(5), 1529-1540

45. Ueno T, Yokota S, Kitaoka T, Wariishi H (2007) Conformational changes in single carboxymethylcellulose chains on a highly oriented pyrolytic graphite surface under different salt conditions. Carbohydr Res 342(7):954-960

46. Aegerter MA, Leventis N, Koebel MM (2011) Aerogels handbook. Springer, New York 
47. Zhang X, Liu X, Yang S, Long K, Wu Y (2012) Effect of carboxyl methyl cellulose on the adhesion properties of sodium silicate wood adhesive. In: Proceedings of international conference on biobase material science and engineering, pp. 230-233

48. Svec F (2010) Porous polymer monoliths: amazingly wide variety of techniques enabling their preparation. J Chromatogr A 1217(6):902-924

49. Kumar S, Bhanjana G, Jangra K, Dilbaghi N, Umar A (2014) Utilization of carbon nanotubes for the removal of rhodamine B dye from aqueous solutions. J Nanosci Nanotechnol 14(6):4331-4336

50. Gopi S, Balakrishnan P, Pius A, Thomas S (2018) Development and modification of cellulose acetate/carboxy methyl cellulose blend films for enhanced adsorption of methylene blue, Macromol Symp 380(1):1800107

51. Doğan M, Özdemir Y, Alkan M (2007) Adsorption kinetics and mechanism of cationic methyl violet and methylene blue dyes onto sepiolite. Dye Pigm 75(3):701-713

52. Gardner DJ, Oporto GS, Mills R, Samir MASA (2008) Adhesion and surface issues in cellulose and nanocellulose. J Adhes Sci Technol 22(5-6):545-567
53. Lin N, Huang J, Dufresne A (2012) Preparation, properties and applications of polysaccharide nanocrystals in advanced functional nanomaterials: a review. Nanoscale 4(11):3274-3294

54. Dutta M, Mishra S, Kaushik M, Basu JK (2011) Application of various activated carbons in the adsorptive removal of methylene blue from aqueous solution. Res J Environ Sci 5(9):741-751

55. Sulak MT, Yatmaz HC (2012) Removal of textile dyes from aqueous solutions with eco-friendly biosorbent. Desalin Water Treat 37(1-3):169-177

56. Boyd RF, Zydney AL (1997) Sieving characteristics of multilayer ultrafiltration membranes. J Membr Sci 131(1-2):155-165

57. El Boujaady H, Mourabet M, El Rhilassi A, Bennani-Ziatni M, Hamri RE, Taitai A (2013) Interaction of adsorption of reactive yellow 4 from aqueous solutions onto synthesized calcium phosphate. J Saudi Chem Soc 21:S94-S100 